\title{
Unique community structure of viruses in a glacier soil of the Tianshan Mountains, China
}

\author{
Li-Li Han ${ }^{1,2} \cdot$ Dan-Ting Yu ${ }^{1,2} \cdot$ Li-Mei Zhang ${ }^{1,2} \cdot$ Jun-Tao Wang ${ }^{1} \cdot$ Ji-Zheng He ${ }^{1,2,3}$
}

Received: 10 September 2016 / Accepted: 15 October 2016/Published online: 24 October 2016

(C) Springer-Verlag Berlin Heidelberg 2016

\begin{abstract}
Purpose Glaciers of the Tianshan Mountains have been geographically isolated for a long time with little human interference. This study aimed to understand the viral community structures and their ecological functions in a unique glacier soil.

Materials and methods The abundances of purified virus particles and bacteria in the glacier soil were examined using epifluorescence microscopy and quantitative PCR of the $16 \mathrm{~S}$ rRNA gene, respectively. Metagenomic analysis was employed to investigate the taxonomic and functional compositions as well as the phylogenetic relationship of the functional genes of the viruses in the glacier soil.

Results and discussion A total of eight double-stranded DNA (dsDNA) virus families were identified in the glacier soil, with Siphoviridae, Podoviridae, and Myoviridae being the more abundant families. The diverse dsDNA viruses and few ssDNA and other types of viruses formed the unique community structure of viruses in the Tianshan Mountains glacier soil. The functional genes identified from the virome mainly
\end{abstract}

Responsible editor: Zhihong Xu

Electronic supplementary material The online version of this article (doi:10.1007/s11368-016-1583-2) contains supplementary material, which is available to authorized users.

\section{Ji-Zheng He}

jzhe@rcees.ac.cn

1 State Key Laboratory of Urban and Regional Ecology, Research Center for Eco-Environmental Sciences, Chinese Academy of Sciences, Beijing 100085, China

2 University of the Chinese Academy of Sciences, Beijing 100049, China

3 Faculty of Veterinary and Agricultural Sciences, The University of Melbourne, Parkville, VIC 3010, Australia belonged to phage-related proteins. The phage terminase of Caudovirales presented high diversity, and its amino acid sequences were different from those in other environments. Conclusions The results showed a unique viral diversity and taxonomic composition in the glacier soil, which suggests the significant ecological role of Caudovirales in this environment.

Keywords Functional composition - Taxonomic diversity · Terminase $\cdot$ Virome $\cdot$ Virus

\section{Introduction}

Viruses are the most abundant biological entities in soil, reaching $10^{9}$ virus particles $\mathrm{g}^{-1}$ soil (Williamson et al. 2005). They can affect the community composition of other microbial groups (Vos et al. 2009; Koskella and Brockhurst 2014); manipulate the life histories and evolution of their host (Rohwer and Thurber 2009); mediate biogeochemical cycles in aquatic environments (Jover et al. 2014); and even threaten plant, animal, and human health. As viruses lack shared phylogenetic biomarkers that can be used for the investigation of their community structures and evolutionary history, such as the $16 \mathrm{~S}$ ribosomal ribonucleic acid (rRNA) gene of bacteria and archaea, viral ecology research is far behind other microbial ecology studies. Following the development of nextgeneration sequencing platforms, most of the metagenomic studies have focused on viruses from many environments. Nevertheless, although a large number of new viruses and their genes have been identified, which has significantly enriched the virus gene database and contributed to the development of the field of viral ecology, our understanding of the soil viruses in different soil types is still in its infancy. 
Over the past years, studies on viral ecology have mainly focused on air (Whon et al. 2012), marine (Breitbart et al. 2002; Angly et al. 2006; Mizuno et al. 2013; Hurwitz et al. 2014; Jover et al. 2014), freshwater (Lopez-Bueno et al. 2009; Rodriguez-Brito et al. 2010; Roux et al. 2012; Cai et al. 2016), soil (Prigent et al. 2005; Prestel et al. 2008; Zablocki et al. 2014, 2016; Adriaenssens et al. 2015), and sediment (Biddle et al. 2011; Yoshida et al. 2013; Dell'Anno et al. 2015) ecosystems. These studies have demonstrated that viral diversity is consistently high in aquatic and soil environments and that double-stranded DNA (dsDNA) viruses are widespread and in relatively high proportion in aquatic and soil ecosystems.

Xinjiang Uygur Autonomous Region is isolated from other regions of China by the Gobi desert in the east, the Altai Mountains in the northeast, and the Qunlun Mountains in the south and is divided into two main parts by the Tianshan Mountains. As a result, Xinjiang has formed its own unique ecological regions. Owing to its significant distance from the oceans, Xinjiang is a well-studied independent territory, which has a typical arid continental climate, with higher evaporation rates than precipitation, wide temperature range between day and night, and abundant sunshine (Han et al. 2009). The Tianshan Mountains no. 51 glacier region is significantly affected by dust activity and anthropogenic sources. The major ions, especially $\mathrm{Na}^{+}$, originate from the dust sources of central Asia and the ocean and are transported by the westerly winds (Dong et al. 2011). To the best of our knowledge, up till now, only a few studies have focused on glacier soil microorganisms, especially viral community structure.

Viruses not only transfer genetic material from one organism to another but also from one ecosystem to another. For instance, some phage sequences have been found to be ubiquitously spread throughout the biosphere (Breitbart et al. 2004; Short and Suttle 2005). Furthermore, there is also evidence that phage can successfully infect and replicate among unrelated environments (Sano et al. 2004). Accordingly, the population composition of viruses in the glacier soil that has been geographically isolated for a long time with little human interference might differ from those in other regions. Therefore, in the present study, we investigated the community composition and the phylogenetic relationship of the functional genes of the viruses in Tianshan Mountains no. 51 glacier soil in Xinjiang.

\section{Materials and methods}

\subsection{Soil sample collection}

Soil sample was collected from no. 51 glacier $\left(43^{\circ} 43^{\prime} \mathrm{N}, 84^{\circ}\right.$ $\left.24^{\prime} \mathrm{E}\right)$, located at the headwaters of the Kuyntun River in the Tianshan Mountains with an area of about $1.48 \mathrm{~km}^{2}$ and maximum length of about $1.7 \mathrm{~km}$. The glacier is about $3610 \mathrm{~m}$ above sea level and surrounded by Gobi desert. To study the viral diversity in the soil under the glacier, approximately $2 \mathrm{~kg}$ of soil sample was collected in August 2015, transported at $4{ }^{\circ} \mathrm{C}$ to our laboratory, and immediately suspended and filtered.

\subsection{Virus extraction and purification}

A total of $250 \mathrm{~g}$ of the glacier soil sample was suspended in 1.51 of glycine solution $(250 \mathrm{mM}, \mathrm{pH}=8.5)$, shaken for $30 \mathrm{~min}$, and centrifuged at $3500 \times \mathrm{g}$ for $10 \mathrm{~min}$ at $4{ }^{\circ} \mathrm{C}$ to precipitate the soil particles. Then, the supernatant was filtered sequentially through $1-\mathrm{mm}, 0.45-\mu \mathrm{m}, 0.20-\mu \mathrm{m}$, and $100-\mathrm{kDa}$ tangential flow filters (QuixStand, GE Healthcare Life Sciences, Pittsburgh, PA, USA). Subsequently, the viruses in the filtrate were concentrated using $30-\mathrm{kDa}$ centrifugal ultrafiltration tubes (Merck Millipore Ltd., Tullagreen, Ireland) until the final sample volume was less than $1 \mathrm{ml}$. Finally, the viral concentrates were treated with DNase I (10 u DNaseI/ $100 \mu \mathrm{l})$ and incubated at $37^{\circ} \mathrm{C}$ for $1 \mathrm{~h}$ to remove free, nonencapsulated DNA. The presence of free and bacterial DNA contaminant was checked by PCR amplification of the $16 \mathrm{~S}$ rRNA gene with primers 27F/1492R (DeLong 1992).

\subsection{Examination of bacterial and viral abundances}

The viral abundances in the soils were estimated by direct counting of virus-like particles under epifluorescence microscope (EFM). Aliquots of the final viral concentrates were suspended in $900 \mu \mathrm{l}$ of sterile deionized water and vacuum filtered through a $25-\mathrm{mm}$-diameter filters consisting of a Whatman Anodisc with a pore size of $0.02 \mu \mathrm{m}$ at a pressure less than $62 \mathrm{kPa}$ for each sample. The filters (with the sample side up) were stained with $100 \mu \mathrm{l}$ of SYBR Gold working solution for $15 \mathrm{~min}$ in dark. The slides were counted immediately using three-dimensional structured illumination microscopy at the Center for Biological Imaging, Institute of Biophysics, Chinese Academy of Sciences (Beijing, China).

The soil total DNA was extracted from $0.25 \mathrm{~g}$ of the soil sample using a MoBio Powersoil® DNA Isolation Kit (MoBio Laboratories, Carlsbad, CA, USA) according to the manufacturer's protocol. The bacterial abundances were quantified by qPCR of the 16S rRNA gene. The 16S rRNA gene was analyzed using 1369f (5'-CGGTGAATACGTTCYCGG$\left.3^{\prime}\right)$ and 1492r (5'-GGWTACCTTGTTACGACTT-3') primers (Suzuki et al. 2000). The qPCRs were performed on an iQTM5 Thermocycler (Bio-Rad Laboratories, CA, USA) with $25 \mu \mathrm{l}$ of the reaction mixture containing $1 \mu \mathrm{l}$ of the extracted DNA, $12.5 \mu \mathrm{l}$ of Power SYBR Green Master Mix (TaKaRa Biotechnology, Dalian, China), and $0.25 \mu \mathrm{M}$ of each primer. The amplification program is as follows: $94{ }^{\circ} \mathrm{C}$ for $5 \mathrm{~min}$, 30 cycles of $94{ }^{\circ} \mathrm{C}$ for $45 \mathrm{~s}, 55^{\circ} \mathrm{C}$ for $30 \mathrm{~s}$, and $72{ }^{\circ} \mathrm{C}$ for $45 \mathrm{~s}$, followed by a plate read at $83^{\circ} \mathrm{C}$. The specificity of the 
amplification products was confirmed by melting curve analysis. After measuring the DNA concentration with NanoDrop ND-2000 UV-Vis Spectrophotometers (NanoDrop Technologies, USA), a known copy number of the plasmid DNA was serially diluted in tenfold steps and subjected to real-time PCR in triplicate to generate an external standard curve. The threshold values obtained from sample amplification were interpolated from the standard curve to determine the number of bacteria found per gram of soil.

\subsection{Viral DNA extraction and high-throughput sequencing}

The viral DNA was extracted from the collected sample using PowerViral Environmental RNA/DNA Isolation Kit (MO BIO Laboratories, Carlsbad, CA, USA). The REPLI-g Single Mini Kit (MDA) (Qiagen, Hilden, Germany) was employed to amplify the total viral DNA to obtain the concentration and quantity needed for high-throughput sequencing. For each sample, $1 \mu \mathrm{g}$ of DNA was fragmented by sonication to a size of $350 \mathrm{bp}$, and the obtained DNA fragments were end-polished, A-tailed, and ligated with the full-length adaptor for Illumina sequencing with further PCR amplification. Clustering of the index-coded samples was performed on a cBot Cluster Generation System according to the manufacturer's instructions. After cluster generation, the library preparations were sequenced on the HiSeq platform (Illumina, San Diego, CA, USA) at Novogene, Beijing, China.

\subsection{Sequence data analysis}

The original sequences of the glacier soil (named BC virome) were uploaded into Metagenomics Rapid Annotation using Subsystem Technology (MG-RAST) v3.6 (Meyer et al. 2008) to perform quality control and automated annotation as well as produce taxonomic and functional assignments. The MG-RAST generates functional categories based on the SEED subsystem database by hierarchical classification. The metagenomes are available on the MG-RAST server under the accession number 4696287.3 for the soil viruses. The rarefaction curve of the BC virome computed by MG-RAST was compared with M5NR using a maximum e-value of $1 \mathrm{e}-5$, minimum identity of $60 \%$, and minimum alignment length of 15 (measured in aa for protein and bp for RNA databases).

Subsequently, the original sequence reads were also performed for quality control and then loaded into Soapdenovo (Luo et al. 2012) with kmer $=59$, no read trimming, and a minimum of 100 reads per contig for sequence assembly. The assembly contigs were uploaded into Metavir2 server (Roux et al. 2014) to annotate viral metagenomic sequences and produce taxonomic assignments. Taxonomic composition was computed from BLAST comparison with the Refseq complete viral genome protein sequence database from NCBI (released on January 19,2016$)$ using BLASTp $(29.65 \%$ of the virome sequences presented a significant hit; the e-value threshold was $10^{-5}$ ) and displayed through Krona.

\subsection{Phylogenetic analysis}

Phylogenetic analysis of the phage terminase was reconstructed using MEGA6 software (Tamura et al. 2013). For the phage terminase tree, reference amino acid sequences were downloaded from the Metavir2 server (Roux et al. 2014). All the amino acid sequences (Table S1, Electronic Supplementary Material) were aligned using ClustalW, and then, the gaps and ambiguously aligned positions were deleted. After alignment, the phylogeny tree was constructed using the Jones-Taylor-Thornton model, maximum likelihood method, and bootstrapping using 1000 replicates for each sequence.

\section{Results}

\subsection{Bacterial and viral abundance}

The abundances of purified virus particles and bacteria from the glacier soil were examined using EFM and qPCR of the $16 \mathrm{~S}$ rRNA gene, respectively. Fluorescence enumeration showed that the dsDNA virus abundance was $4.35 \times 10^{9}$ virus particles $\mathrm{g}^{-1}$ soil (dry weight). Quantitative PCR assays revealed that the $16 \mathrm{~S}$ rRNA gene abundance was $2.76 \times 10^{9}$ copies $\mathrm{g}^{-1}$ soil (dry weight). The dsDNA virus to bacteria abundance ratio in the glacier soil was 1.6.

\subsection{Sequence analysis of the $\mathrm{BC}$ virome}

Pyrosequencing of the $\mathrm{BC}$ virome resulted in $13,327,792$ raw reads, with an average length of $153 \mathrm{bp}$. The metagenomic preliminary analysis results were computed by MG-RAST, and a total of $1,836,368$ reads with a 144-bp average length passed the quality control. The mean GC percent was $48 \%$ for clean data, and most of the predicted protein sequences $(93.6 \%)$ were orphans (no significant matches to translated gene in a BLASTX search of the SEED non-redundant database). In addition, only $0.08 \%$ of the annotated sequences were identified as rRNA features, and $62.2 \%$ of the identified protein features were functional categories. The rarefaction curve of the BC virome (Fig. S1, Electronic Supplementary Material) computed by MG-RAST showed 3050 species count cluster at a minimum identity of $60 \%$ for the $13,327,000$ reads that were uploaded. As the rarefaction curve neared an asymptote, we assumed that a substantial fraction of the viral richness was sampled. The alpha diversity, determined based on a species-level annotation, summarizes the diversity of organisms in a sample with a single number, and the annotated species richness indicates the number of distinct 
species annotations in the combined MG-RAST dataset. The species diversity of the BC virome was 263.5 species, which are relatively lower than that of open soil and hypolith (344.5 and 1058.4 species, respectively) (Zablocki et al. 2014).

Contig assembly was performed to circumvent the short read lengths generated with the Illumina platform for open reading frame $(\mathrm{ORF})$ prediction and annotation. A total of 3723 contigs larger than 500 bp were assembled with Soapdenovo software, and the longest contig was $14,975 \mathrm{bp}$.

\subsection{Viral diversity and taxonomic composition}

A total of 3723 contigs larger than 500 bp were uploaded for analysis of the $\mathrm{BC}$ viral taxonomic composition. According to the Metavir2 annotation, 1104 contigs had homology to known viral sequences through the GAAS (genome length normalization) taxonomic composition plot (Fig. 1) with an e-value threshold of $10^{-5}$. The majority $(96 \%)$ of the contigs showing similarity to dsDNA viruses belonged to the order Caudovirales, with Siphoviridae being the most abundance family (37\%), followed by Podoviridae (23\%) and Myoviridae (22\%). Furthermore, $3 \%$ of the contigs shared identity with unclassified Caudovirales. The other dsDNA viruses identified at an abundance of 0.09-3\% included Phycodnaviridae, Mimiviridae, Iridovirus, Tectivirus, and Chordopoxvirinae (Fig. S2, Electronic Supplementary Material). In addition, there were also smaller numbers of contigs that matched the single-stranded DNA (ssDNA) virus families $(0.9 \%)$ in the $\mathrm{BC}$ virome, including Inovirus, Alphatorquevirus, and Circovirus-like. All these formed the unique community structure of viruses in Tianshan Mountains no. 51 glacier soil.

\subsection{Functional composition analysis}

Functional annotation of the $\mathrm{BC}$ virome was performed by MG-RAST and resulted in 546,018 functional hits. A total of 28 functional categories were assigned to the BC libraries; the majority $(65.8 \%)$ of which belonged to phages, prophages, transposable elements, and plasmids (Fig. 2a). Other relatively prominent subsystems ( $>1 \%$ ) included clusteringbased subsystems, DNA metabolism, cell wall and capsule, membrane transport, nucleosides and nucleotides, and fatty acids, lipids, and isoprenoids. Furthermore, there were several metabolic pathways involving nitrogen, phosphorus, sulfur, potassium, iron, aromatic compound, RNA, and protein metabolism-related subsystems. However, only $1.4 \%$ of the virulence, disease, and defense subsystem was functionally annotated, which were pathogenic bacteria or phage infection-related proteins.

The subsystem of phages, prophages, transposable elements, and plasmids was further investigated and identified as 19 phage-related proteins (Fig. 2b); most of them are phage tail fiber proteins $(37.2 \%)$, r1t-like streptococcal phage $(23.4 \%)$, and phage tail proteins $2(21.3 \%)$. In this analysis, phage-related functional genes in the $\mathrm{BC}$ virome were overrepresented compared to functional categories in other types of viruses.

\subsection{Phylogenetic analysis}

As dsDNA viruses presented the highest abundance in the glacier soil examined, we constructed the phylogenetic tree with terminase amino acid sequences annotated in the Metavir2 analysis, which resembled the phage terminase of Caudovirales, and compared it with the terminase of a wide range of known Caudovirales viruses and related metagenomic samples. Figure 3 shows an abridged version of the phylogenetic tree for clarity, and the complete tree is illustrated in Fig. S3, Electronic Supplementary Material. The reference sequences of Caudovirales were distinguished by different colors according to Metavir2 annotation, such as purple for Myoviridae, green for Siphoviridae, and blue for Podoviridae. A total of 19 terminase amino acid sequences (Table S1, Electronic Supplementary Material) were collected from the BC contigs. According to gene annotation information from Metavir2 database, 14 genes formed four clusters dispersed with the Siphoviridae group (light green background in Fig. 3), three genes clustered with Podoviridae viruses (light blue background in Fig. 3), and two genes belonged to the Myoviridae group (light purple background in Fig. 3). Furthermore, the sequences from the BC virome were very much dispersed within the Caudovirales group. These results indicated that diverse dsDNA viruses occurred in no. 51 glacier soil with less human inference.

\section{Discussion}

The present study showed that the dsDNA viral abundance in the glacier soil was $4.4 \times 10^{9}$ virus particles $\mathrm{g}^{-1}$ soil (dry weight). However, it should be noted that only dsDNA could be labeled by fluorescent through EFM method, while ssDNA viruses cannot be detected. Also, the nucleic acid extraction method applied in the present study excluded RNA viruses, and therefore, our data may not reflect the complete viral abundance in the glacier soil. Previous study showed that there were approximately $1.3-4.2 \times 10^{9}$ virions in forest soils and $8.7 \times 10^{8}$ to $1.1 \times 10^{9}$ agricultural soils (Williamson et al. $2005), 1.5 \sim 6.4 \times 10^{8}$ virus particles in arid desert soils (Zablocki et al. 2016), and 1.1-1.2 $\times 10^{9}$ virions in wheat rhizosphere soil (Swanson et al. 2009); all these viral particles were tested in per gram dry weight soil by transmission electron microscopy (TEM). In the analysis of virus abundance under EFM and TEM, the extraction procedure may have 
Fig. 1 Taxonomic composition of the $\mathrm{BC}$ virome. Composition type was GAAS (genome length normalization) with an e-value threshold of $10^{-5}$, as generated by Metavir2. The most abundant viral taxa are indicated in red, while yellow, green, blue, and purple indicate the subsequent abundant viral taxa, respectively

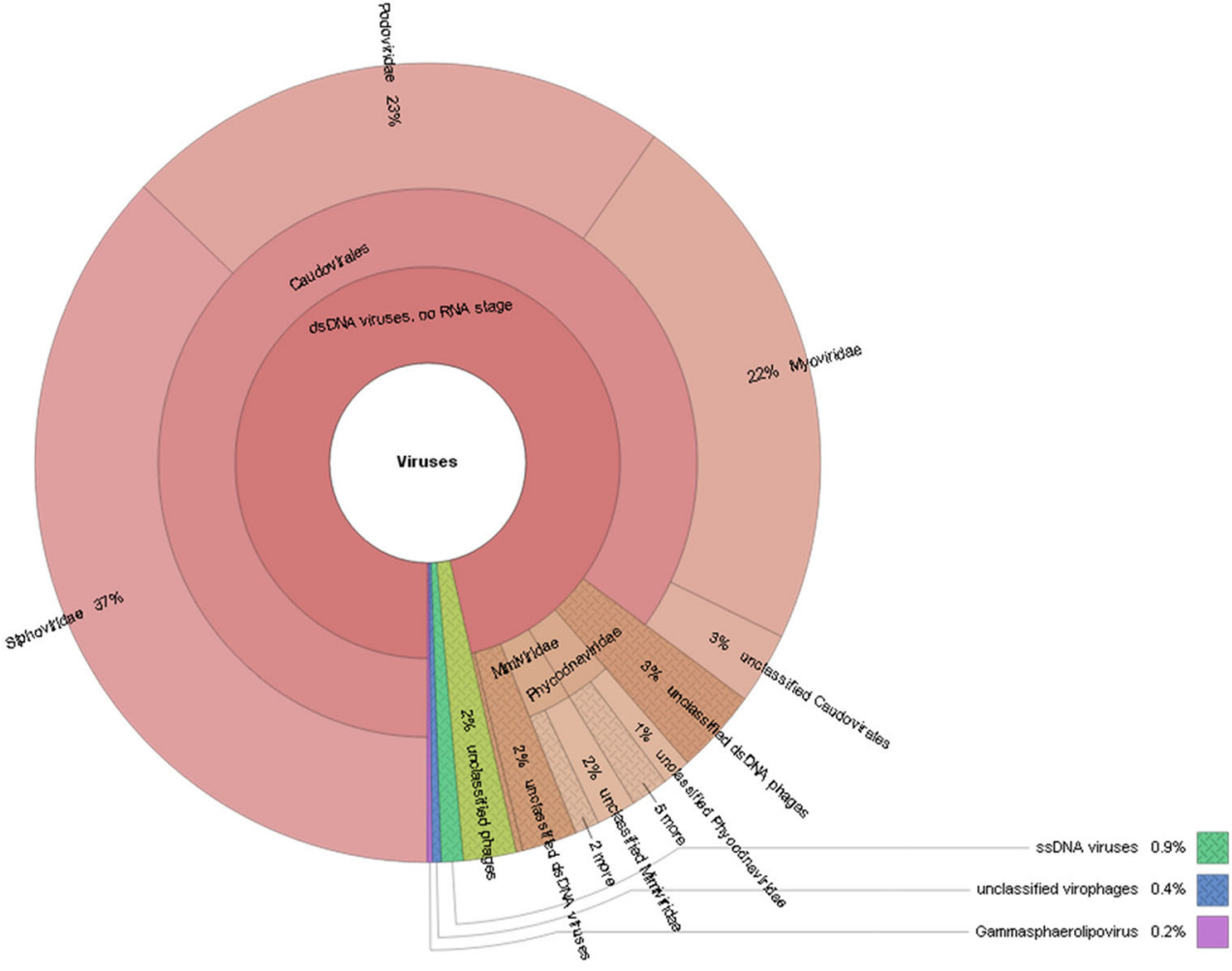

a

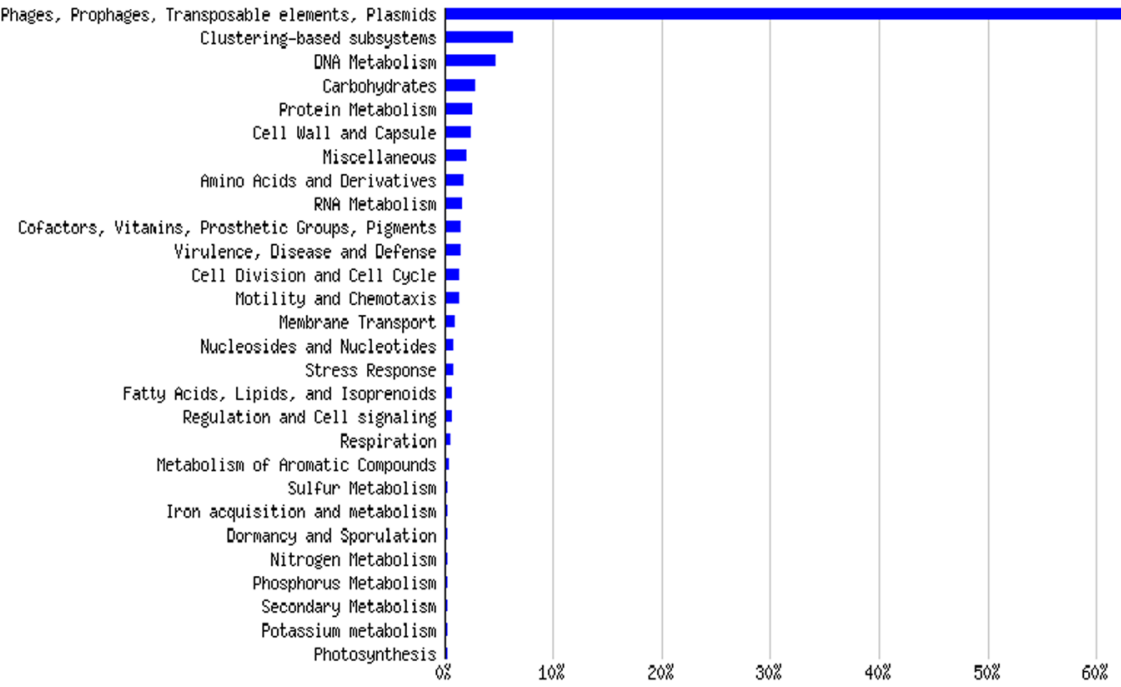

b

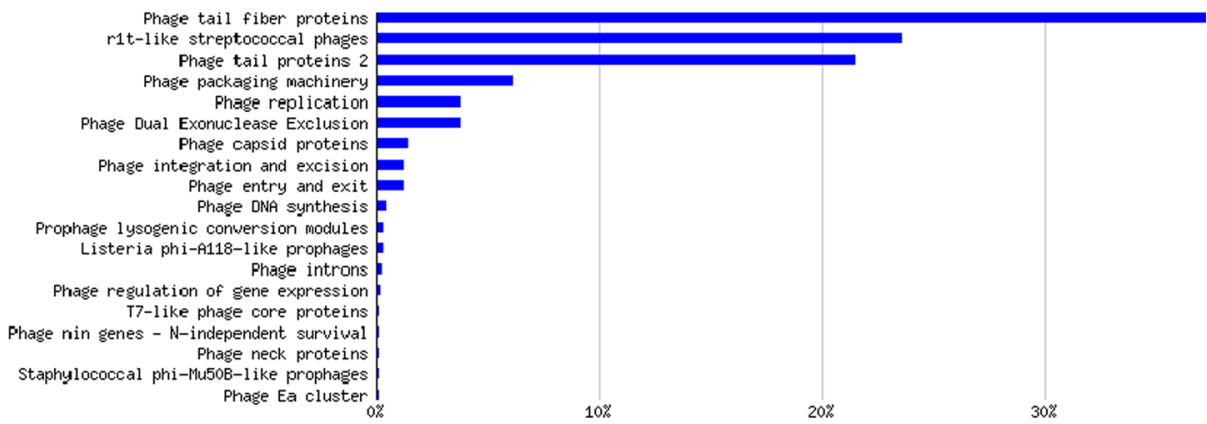


Fig. 3 Phylogenetic tree of phage terminase amino acid sequences determined by Metavir2. The tree is bootstrapped with 1000 subreplicates, and confidence levels $>50 \%$ are indicated at the internodes. The scale bar represents an amino acid substitution per site. The purplecolored sequence names indicate Myoviridae, green-colored sequence names stand for Siphoviridae, and blue-colored sequence names represent Podoviridae

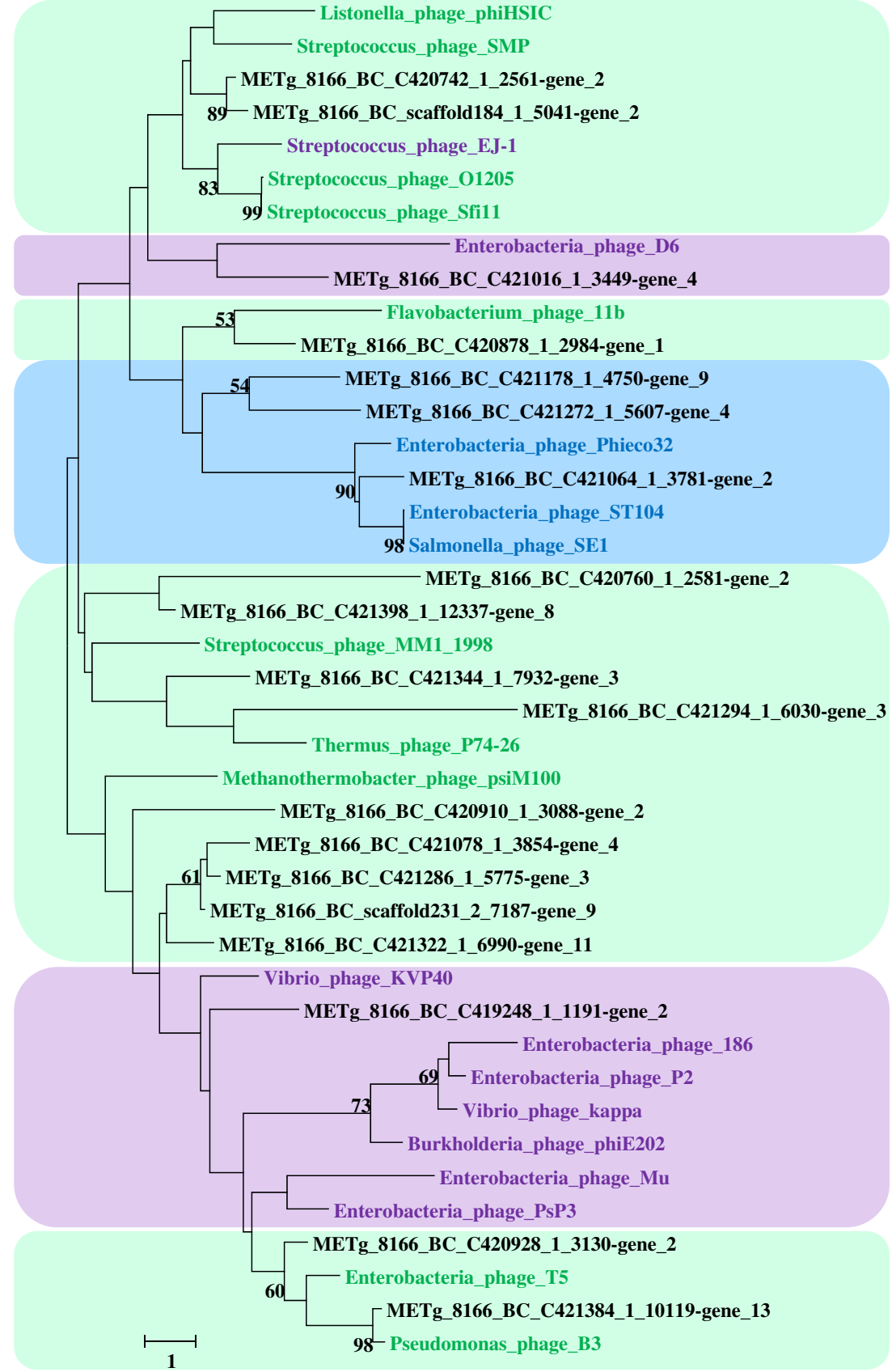

easily resulted in phage tail breakage (Williamson et al. 2005), and sample transportation from Tianshan to our lab in Beijing may have caused a small portion of virus degradation; therefore, the number of virus particles determined by EFM and TEM might have been underestimated. Thus, future work will focus on developing new protocols for viral enumeration, such as PCR-based analysis.

Moreover, diverse dsDNA viruses and few ssDNA and other types of viruses were identified from the glacier soil sample. A total of eight dsDNA virus families were identified; Caudovirales was the most abundant viral order, and Phycodnaviridae and Mimiviridae viruses were the second- most abundant taxa. A recent study showed that viruses are predominantly found in similar habitats, regardless of their geographic proximity according to the global maps of viral biogeography (Paez-Espino et al. 2016). In this study, the virus diversity observed in the glacier soil showed similar taxonomic composition but different abundance to that found in Antarctic open soil (Zablocki et al. 2014) and Namib desert (Adriaenssens et al. 2015). The viral community structure in glacier soil characterized by high levels of bacterial lysogens and low extracellular virus counts may be derived by multiplicity factor, such as temperature, water availability, geographic distances, and habitat type. Until now, no clear 
Table 1 Taxonomic composition of metagenomes in different types of samples by Metavir analysis

\begin{tabular}{|c|c|c|c|c|c|c|c|c|}
\hline \multirow[t]{2}{*}{ Systems } & \multirow[t]{2}{*}{ Location } & \multicolumn{6}{|c|}{ Percent of total sequences } & \multirow[t]{2}{*}{ Reference } \\
\hline & & Group & & Order & & Family & & \\
\hline \multirow[t]{2}{*}{ Air } & Industrial complex in Seoul, South Korea & ssDNA & 78 & Unclassified & 37 & Circoviridae & 24 & Whon et al. (2012) \\
\hline & Residential district in Seoul, South Korea & ssDNA & 39 & Unclassified & 35 & & & \\
\hline \multirow[t]{4}{*}{ Seawater } & Iquique, Chile (10 m) & dsDNA & 81 & Caudovirales & 66 & Myoviridae & 39 & Cassman et al. (2012) \\
\hline & Iquique, Chile (90 m) & dsDNA & 56 & Caudovirales & 39 & & & \\
\hline & & ssDNA & 43 & Circoviridae & 33 & & & \\
\hline & Iquique, Chile (200 m) & dsDNA & 89 & Caudovirales & 73 & Myoviridae & 39 & \\
\hline Seawater & Northern Line Islands & dsDNA & 100 & Caudovirales & 83 & & & Dinsdale et al. (2008) \\
\hline \multirow[t]{3}{*}{ Seawater } & Indian Ocean & dsDNA & 99 & Caudovirales & 79 & Myoviridae & 27 & Williamson et al. (2012) \\
\hline & & & & & & Podoviridae & 32 & \\
\hline & & & & & & Siphoviridae & 17 & \\
\hline Freshwater & Lake Limnopolar, Antarctica & ssDNA & 50 & Microviridae & 40 & & & Lopez-Bueno et al. (2009) \\
\hline \multirow[t]{7}{*}{ Freshwater } & Lake Bourget in France & dsDNA & 67 & Caudovirales & 54 & Myoviridae & 18 & Roux et al. (2012) \\
\hline & & & & & & Podoviridae & 15 & \\
\hline & & & & & & Siphoviridae & 19 & \\
\hline & & ssDNA & 37 & Microviridae & 30 & & & \\
\hline & Lake Pavin in France & dsDNA & 80 & Caudovirales & 66 & Myoviridae & 25 & \\
\hline & & & & & & Podoviridae & 13 & \\
\hline & & & & & & Siphoviridae & 29 & \\
\hline \multirow[t]{3}{*}{ Freshwater } & Salton Sea (Kent SeaTech) in USA & dsDNA & 98 & Caudovirales & 93 & Myoviridae & 19 & Rodriguez-Brito et al. (2010) \\
\hline & & & & & & Podoviridae & 46 & \\
\hline & & & & & & Siphoviridae & 27 & \\
\hline \multirow[t]{3}{*}{ Freshwater } & Jiulong River in China & dsDNA & 99 & Caudovirales & 84 & Myoviridae & 26 & Cai et al. (2016) \\
\hline & & & & & & Podoviridae & 31 & \\
\hline & & & & & & Siphoviridae & 23 & \\
\hline \multirow[t]{3}{*}{ Sediment } & Izu-Ogasaware Trench & ssDNA & 81 & Microviridae & 74 & & & Yoshida et al. (2013) \\
\hline & Mariana Trench & ssDNA & 76 & Circoviridae & 36 & Gokushovirinad & 32 & \\
\hline & Shimokita Peninsula & ssDNA & 97 & Microviridae & 36 & Circoviridae & 50 & \\
\hline Sediment & Arctic Ocean & ssDNA & 68 & Inoviridae & 45 & dsDNA & 29 & Dell'Anno et al. (2015) \\
\hline Sediment & Brazos-Trinity Basin in Mexico & dsDNA & 95 & Caudovirales & 51 & Phycodnaviridae & 20 & Biddle et al. (2011) \\
\hline \multirow[t]{3}{*}{ Soil } & Antarctic open soil & dsDNA & 76 & Caudovirales & 70 & Myoviridae & 25 & Zablocki et al. (2014) \\
\hline & & & & & & Podoviridae & 15 & \\
\hline & & & & & & Siphoviridae & 27 & \\
\hline \multirow[t]{3}{*}{ Soil } & Namib desert & dsDNA & 80 & Caudovirales & 75 & Myoviridae & 9 & Adriaenssens et al. (2015) \\
\hline & & & & & & Podoviridae & 10 & \\
\hline & & & & & & Siphoviridae & 48 & \\
\hline \multirow[t]{2}{*}{ Soil } & Coastal soil in Scotland & ssDNA & 88 & Microviridae & 84.6 & & & Reavy et al. (2015) \\
\hline & Brown Earth in Scotland & ssDNA & 71.6 & Microviridae & 50.3 & & & \\
\hline \multirow[t]{3}{*}{ Soil } & Tianshan Mountains no. 51 glacier & dsDNA & 96 & Caudovirales & 85 & Myoviridae & 22 & This study \\
\hline & & & & & & Podoviridae & 22 & \\
\hline & & & & & & Siphoviridae & 38 & \\
\hline
\end{tabular}

explanation for this division could be offered, and the dispersal pattern was not quite obvious in soils owing to the limitation of samples.
We compared the glacier soil viral composition with selected viromes in Metavir2 (Table 1), spanning different types of samples, including air, seawater, freshwater, sediment, and 
soil. The prevalence of Caudovirales as the dominant taxon was observed in most of the seawater (Dinsdale et al. 2008; Cassman et al. 2012; Williamson et al. 2012) and freshwater (Rodriguez-Brito et al. 2010; Roux et al. 2012; Cai et al. 2016) samples and in some of the soil samples (Biddle et al. 2011; Zablocki et al. 2014; Adriaenssens et al. 2015). On comparing the families within the Caudovirales, Podoviridae and Myoviridae represented the major fraction in aquatic environments, and Siphoviridae were dominant in soil environments, including the glacier soil sample examined in the present study.

An alternative approach to investigate the community composition and diversity of viruses is to assign the phylogeny of signature genes. The marker gene with the most hits in the BC virome, as determined by Metavir2, was the terminase gene, which was mainly present in the Caudovirales order. In current study, the terminase gene terL, required for packaging initiation in members of the Caudovirales, was the most common in many soil habitats (Black 1995; Zablocki et al. 2016). A phylogenetic tree was generated from the contig sequences, which showed that most of the $\mathrm{BC}$ virome ter $L$ gene amino acid sequences clustered separately from the reference sequences of the cultured tailed phages and related metagenomic samples (Fig. S2, Electronic Supplementary Material). These results are consistent with taxonomic classification in the $\mathrm{BC}$ virome. It has been hypothesized that despite the very high local viral diversity, the total global diversity is limited by worldwide movement of virions, because viruses can move throughout the world and contribute to a global genetic pool (Breitbart and Rohwer 2005). The present study showed that the viruses in the glacier soil had high local viral diversity and their functional genotypes differed from those in other environments, which might be owing to the blocking of communications among bacteria and restriction of virus movement, resulting in the formation of a specific viral community structure in the glacier soil.

Our study could lead to a more comprehensive understanding of the viral distribution pattern in the glacier soil, as well as facilitate building global maps of soil viral biogeography in the nearest future. Further efforts on detailed sequencing using third-generation sequencing technology may benefit to identify new virus species and achieve longer viral contigs that probably represent more abundant viral populations.

\section{Conclusions}

The results of the present study demonstrated a unique viral diversity and taxonomic composition as well as the significant ecological role of Caudovirales in no. 51 glacier soil. The functional genes identified from the $\mathrm{BC}$ virome mainly belonged to phage-related proteins. Furthermore, the phage terminase of Caudovirales exhibited high diversity in the
$\mathrm{BC}$ virome, and its terminase amino acid sequences were different from those in other environments. The observed abundance as well as taxonomic and functional diversities of the viruses in the glacier soil could aid future soil viromic studies on a larger spatial scale and enhance our understanding of the ecological functions of soil viruses.

Acknowledgments This work was supported by the National Science Foundation of China (Grant Nos. 41571248 and 41301265).

\section{References}

Adriaenssens EM, Van Zyl L, De Maayer P, Rubagotti E, Rybicki E, Tuffin M, Cowan DA (2015) Metagenomic analysis of the viral community in Namib desert hypoliths. Environ Microbiol 17:480 495

Angly FE, Felts B, Breitbart M, Salamon P, Edwards RA, Carlson C, Chan AM, Haynes M, Kelley S, Liu H, Mahaffy JM, Mueller JE, Nulton J, Olson R, Parsons R, Rayhawk S, Suttle CA, Rohwer F (2006) The marine viromes of four oceanic regions. PLoS Biol 4: 2121-2131

Biddle JF, White JR, Teske AP, House CH (2011) Metagenomics of the subsurface Brazos-Trinity Basin (IODP site 1320): comparison with other sediment and pyrosequenced metagenomes. ISME J 5:10381047

Black LW (1995) DNA packaging and cutting by phage terminases: control in phage T4 by a synaptic mechanism. BioEssays 17: $1025-1030$

Breitbart M, Rohwer F (2005) Here a virus, there a virus, everywhere the same virus? Trends Microbiol 13:278-284

Breitbart M, Salamon P, Andresen B, Mahaffy JM, Segall AM, Mead D, Azam F, Rohwer F (2002) Genomic analysis of uncultured marine viral communities. PNAS 99:14250-14255

Breitbart M, Miyake JH, Rohwer F (2004) Global distribution of nearly identical phage-encoded DNA sequences. FEMS Microbiol Lett 236:249-256

Cai L, Zhang R, He Y, Feng X, Jiao N (2016) Metagenomic analysis of virioplankton of the subtropical Jiulong River estuary, China. Viruses 8:35

Cassman N, Prieto-Davó A, Walsh K, Silva GG, Angly F, Akhter S, Barott K, Busch J, McDole T, Haggerty JM (2012) Oxygen minimum zones harbour novel viral communities with low diversity. Environ Microbiol 14:3043-3065

Dell'Anno A, Corinaldesi C, Danovaro R (2015) Virus decomposition provides an important contribution to benthic deep-sea ecosystem functioning. PNAS 112:E2014-E2019

DeLong EF (1992) Archaea in coastal marine environments. PNAS 89: 5685-5689

Dinsdale EA, Edwards RA, Hall D, Angly F, Breitbart M, Brulc JM, Furlan M, Desnues C, Haynes M, Li L (2008) Functional metagenomic profiling of nine biomes. Nature 452:629-632

Dong Z, Li Z, Zhang M, Wang F, Wu L (2011) Physico-chemical characteristics and environmental significance of snow deposition on Haxilegen glacier no. 51 in Tian Shan, China. JMS 8:484-494

Han LL, Wang ET, Han TX, Liu J, Sui XH, Chen WF, Chen WX (2009) Unique community structure and biogeography of soybean rhizobia in the saline-alkaline soils of Xinjiang, China. Plant Soil 324:291305

Hurwitz BL, Westveld AH, Brum JR, Sullivan MB (2014) Modeling ecological drivers in marine viral communities using comparative metagenomics and network analyses. PNAS 111:10714-10719 
Jover LF, Effler TC, Buchan A, Wilhelm SW, Weitz JS (2014) The elemental composition of virus particles: implications for marine biogeochemical cycles. Nat Rev Microbiol 12:519-528

Koskella B, Brockhurst MA (2014) Bacteria-phage coevolution as a driver of ecological and evolutionary processes in microbial communities. FEMS Microbiol Rev 38:916-931

Lopez-Bueno A, Tamames J, Velazquez D, Moya A, Quesada A, Alcami A (2009) High diversity of the viral community from an Antarctic Lake. Science 326:858-861

Luo R, Liu B, Xie Y, Li Z, Huang W, Yuan J, He G, Chen Y, Pan Q, Liu Y (2012) SOAPdenovo2: an empirically improved memory-efficient short-read de novo assembler. Giga Science 1:1-6

Meyer F, Paarmann D, D'Souza M, Olson R, Glass EM, Kubal M, Paczian T, Rodriguez A, Stevens R, Wilke A (2008) The metagenomics RAST server - a public resource for the automatic phylogenetic and functional analysis of metagenomes. BMC Bioinformatics 9:386

Mizuno CM, Rodriguez-Valera F, Kimes NE, Ghai R (2013) Expanding the marine virosphere using metagenomics. PLoS Genet 9: e1003987

Paez-Espino D, Eloe-Fadrosh EA, Pavlopoulos GA, Thomas AD, Huntemann M, Mikhailova N, Rubin E, Ivanova NN, Kyrpides NC (2016) Uncovering Earth's virome. Nature 536:425-430

Prestel E, Salamitou S, DuBow MS (2008) An examination of the bacteriophages and bacteria of the Namib desert. J Microbiol 46:364 372

Prigent M, Leroy M, Confalonieri F, Dutertre M, DuBow MS (2005) A diversity of bacteriophage forms and genomes can be isolated from the surface sands of the Sahara desert. Extremophiles 9:289-296

Reavy B, Swanson MM, Cock PJ, Dawson L, Freitag TE, Singh BK, Torrance L, Mushegian AR, Taliansky M (2015) Distinct circular single-stranded DNA viruses exist in different soil types. Appl Environ Microbiol 81:3934-3945

Rodriguez-Brito B, Li L, Wegley L, Furlan M, Angly F, Breitbart M, Buchanan J, Desnues C, Dinsdale E, Edwards R (2010) Viral and microbial community dynamics in four aquatic environments. ISME J 4:739-751

Rohwer F, Thurber RV (2009) Viruses manipulate the marine environment. Nature 459:207-212

Roux S, Enault F, Robin A, Ravet V, Personnic S, Theil S, Colombet J, Sime-Ngando T, Debroas D (2012) Assessing the diversity and specificity of two freshwater viral communities through metagenomics. PLoS One 7:e33641
Roux S, Tournayre J, Mahul A, Debroas D, Enault F (2014) Metavir 2: new tools for viral metagenome comparison and assembled virome analysis. BMC Bioinformatics 15:1

Sano E, Carlson S, Wegley L, Rohwer F (2004) Movement of viruses between biomes. Appl Environ Microbiol 70:5842-5846

Short CM, Suttle CA (2005) Nearly identical bacteriophage structural gene sequences are widely distributed in both marine and freshwater environments. Appl Environ Microbiol 71:480-486

Suzuki MT, Taylor LT, DeLong EF (2000) Quantitative analysis of smallsubunit rRNA genes in mixed microbial populations via 5'-nuclease assays. Appl Environ Microbiol 66:4605-4614

Swanson MM, Fraser G, Daniell TJ, Torrance L, Gregory PI, Taliansky M (2009) Viruses in soils: morphological diversity and abundance in the rhizosphere. Ann Appl Biol 155:51-60

Tamura K, Stecher G, Peterson D, Filipski A, Kumar S (2013) MEGA6: Molecular Evolutionary Genetics Analysis version 6.0. Mol Biol Evol 30:2725-2729

Vos M, Birkett PJ, Birch E, Griffiths RI, Buckling A (2009) Local adaptation of bacteriophages to their bacterial hosts in soil. Science 325: 833-833

Whon TW, Kim M-S, Roh SW, Shin N-R, Lee H-W, Bae J-W (2012) Metagenomic characterization of airborne viral DNA diversity in the near-surface atmosphere. J Virol 86:8221-8231

Williamson KE, Radosevich M, Wommack KE (2005) Abundance and diversity of viruses in six Delaware soils. Appl Environ Microbiol 71:3119-3125

Williamson SJ, Allen LZ, Lorenzi HA, Fadrosh DW, Brami D, Thiagarajan M, McCrow JP, Tovchigrechko A, Yooseph S, Venter JC (2012) Metagenomic exploration of viruses throughout the Indian Ocean. PLoS One 7:e42047

Yoshida M, Takaki Y, Eitoku M, Nunoura T, Takai K (2013) Metagenomic analysis of viral communities in (hado) pelagic sediments. PLoS One 8:e57271

Zablocki O, van Zyl L, Adriaenssens EM, Rubagotti E, Tuffin M, Cary SC, Cowan D (2014) High-level diversity of tailed phages, eukaryote-associated viruses, and virophage-like elements in the metaviromes of Antarctic soils. Appl Environ Microbiol 80:68886897

Zablocki O, Adriaenssens EM, Cowan D (2016) Diversity and ecology of viruses in hyperarid desert soils. Appl Environ Microbiol 82:770 777 